\title{
ALTERNATIVO
}

\section{A RELAÇÃO MÉDICO-PACIENTE: OBSERVAÇÃO PARTICIPANTE EM VISITAS DOMICILIARES}

\author{
Francinete Alves de Oliveira Giffoni(1) \\ Gislene Farias de Oliveira(2) \\ Juliana Monteiro Abreu(3)
}

\section{RESUMO}

A utilização excessiva de procedimentos tecnológicos vem cada vez mais afastando o médico da cabeceira do doente, fazendo com que a relação médico-paciente - tão importante e valorizada no passado - seja substituída pela solicitação de exames complementares cada vez mais sofisticados, em detrimento da história clínica e do exame físico. O método da observação participante se constitui um importante recurso em pesquisa qualitativa no campo da saúde. Ela favorece o contato mais próximo do profissional com a comunidade, e uma percepção contextualizada do fenômeno saúde/doença. O objetivo foi demonstrar a importância do método da observação participante como oportunidade potencialmente transformadora para estudantes de medicina que podem refletir sobre a relação médicopaciente a partir de pesquisas em saúde comunitária. O trabalho foi realizado através de observação participante em visitas domiciliares de estudantes do quarto semestre do curso de medicina a 60 residências escolhidas aleatoriamente na área de abrangência de 14 postos do Programa de Saúde da Família no município de Barbalha. Utilizou-se o método de análise de discurso para o tratamento dos dados colhidos nos diários de campo dos alunos. Os resultados demonstraram três aspectos importantes: a) uma maior compreensão das crenças populares em relação à doença e a cura; b) o desenvolvimento da empatia; e c) uma preocupação com o aperfeiçoamento da relação médico-paciente, a partir desta experiência de pesquisa na comunidade. Concluiu-se que aprofundar uma reflexão sobre a complexidade do exercício do profissional de saúde implica repensar a relação médico-paciente como uma forma de reafirmar a medicina e as demais profissões de saúde como práticas muito mais humana do que técnica-científicsa.

Palavras-chave: Relação médico-paciente, Cultura, Saúde/Doença.

(1) Médica, Professora da Universidade Federal do Ceará, mestre em educação e doutoranda em educação pela Universidade Federal do Ceará. (francinetealves@gmail.com);

(2) Psicóloga, Professora da Universidade Regional do Cariri e da Universidade Federal do Ceará, doutoranda em Psicologia Social pela Universidade Federal da Paraíba (gislenefo@hotmail.com).

(3) Acadêmica de Medicina da Universidade Federal do Ceará (july_abreu@hotmail.com). 
A utilização excessiva de procedimentos tecnológicos vem cada vez mais afastando o médico da cabeceira do doente, fazendo com que a relação médico-paciente - tão importante e valorizada no passado - seja substituída pela solicitação de exames complementares cada vez mais sofisticados, em detrimento da história clínica e do exame físico (OLIVEIRA JÚNIOR, 2005)

As novas tecnologias trouxeram muitos benefícios, porém, o médico foi ficando cada vez mais afastado do doente como ser humano. Dessa forma, tanto profissionais, quanto pacientes tem se mostrado insatisfeitos com uma maneira mais impessoal de tratar.

Hoje, o doente está sendo reduzido a exames complementares, perdendo-se assim a visão integral do ser humano (OLIVEIRA JÚNIOR, 2005).

Uma preocupação importante da categoria hoje é com relação a possibilidade de perda da perspectiva humana na Medicina. Neste caso, concentrando o olhar do médico doença, e não na pessoa enferma.

O paciente deseja ser tratado como uma pessoa, e não como um caso ou um número de estatística. Em resumo, pede para ser reconhecido como alguém no mundo impessoal da Medicina. Não encontrar a atenção desejada pode trazer-lhe dor moral, bem como a sensação de abandono e frustração, acarretando, assim, a dificuldade no tratamento (TEIXEIRA e DANTAS, 1997).

Não podemos esquecer que o efeito terapêutico do médico depende da sua capacidade de influenciar postivamente o paciente, aliado à explicação clara sobre a doença e os meios diagnósticos e tratamentos a serem utilizados. As máquinas não poderão jamais aquilatar nem compreender o sofrimento humano, tampouco sanar os temores e angústias do paciente (ROGERS e STEVENS, 1991). Segundo o autor,

O declínio vivenciado hoje na relação médico-paciente deve-se em parte à atual formação médica que, continua privilegiando o lado organicista e tecnicista em detrimento de uma formação de caráter psicossomático. (OLIVEIRA JÚNIOR, 2005, p.2).

Esta situação poderia implicar em que muitos profissionais tenham dificuldade em lidar com questões emocionais e afetivas, o que pode acarretar uma relação cada vez mais impessoal, na qual apenas os aspectos técnicos são mais valorizados que o discurso ou os sinais corporais. 
Com o advento da Bioética, a relação médico-paciente vem sendo mais estudada e a literatura internacional, reportando-se a modelos de avaliação que variam desde observações participantes até a construção de escalas, passando por entrevistas e questionários de autoresposta (SOARES, 1997). A observação participante se constitui um importante recurso em pesquisa qualitativa no campo da saúde. Ela favorece o contato mais próximo do profissional com a comunidade, e uma percepção contextualizada do fenômeno saúde/doença.

O objetivo do presente estudo foi demonstrar a importância do método da observação participante como oportunidade potencialmente transformadora para estudantes de medicina que podem refletir sobre a relação médico-paciente a partir de pesquisas em saúde comunitária.

Para atender ao objetivo foram realizadas observações participantes em visitas domiciliares de estudantes do quarto semestre do curso de medicina a 60 residências escolhidas aleatoriamente na área de abrangência de 14 postos do PSF no município de Barbalha.

Utilizou-se o método de análise de discurso para o tratamento dos dados colhidos nos diários de campo dos alunos, por ser mais apropriada como suporte teórico para estudo da emergência de saberes populares, elaborados no âmbito dos fenômenos comunicacionais, pertinente ao universo vivencial do grupo pesquisado. Dessa forma foi possível a identificação do modo de pensar e dos sentimentos experienciados pelos alunos durante a atividade de campo. Além disso, possibilitou a compreensão de aspectos da construção da subjetividade dos entrevistados em relação a saúde-doença, quanto a suas percepções sobre a relação médico-paciente.

\section{Resultados}

Os discursos dos alunos, demonstraram três aspectos importantes:

O primeiro, denota uma Compreensão das crenças populares em relação à doença e a cura, que pode ser evidenciada nos seguintes trechos dos discursos: “...Percebi que a religiosidade continua presente na vida das pessoas, principalmente entre os mais humildes...”; “...foi bom ouvir associações entre Deus, santos e a possibilidade de cura...”; “... tem certeza que Deus lhe curou...”; “... é interessante conhecer o aspecto da religião e da ciência no processo saúde-doença” (Observe-se que neste caso, o aluno constata a 
dimensão humana da religiosidade presente na família que ele visita); “...acho importante o conhecimento dos hábitos, crenças e expressões populares no processo de assistência à saúde...”; “... achei interessante o fato de como essas pessoas acreditam realmente que suas rezas e sua fé, influenciam no processo de cura. Elas se sentem mais felizes e mais seguras...”; “... acredito que o homem tem o dom de superar qualquer obstáculo, para isso precisa de alicerces: crença verdadeira, uma religião, uma família bem estruturada e estabilidade com grupos sociais...”; “ ... percebi que apesar de diferença sócio-cultural, a idéia de saúde-doença no modelo biomédico já é bem aceito, mesmo nas classes mais desprovidas de estudo..." (Neste caso, há a constatação por parte do aluno de que a população aceita bem o modelo biomédico).

O segundo, nos leva a perceber um Desenvolvimento da empatia, por parte dos alunos, que pode ser evidenciada nos seguintes trechos dos discursos: “...me senti emocionado por saber o quanto a pessoa que é entrevistada tem medo de sua própria doença...”; “... senti uma enorme satisfação ao perceber que conseguimos faze-la confiar em nós...” (Durante a visita os alunos já demosntram preocupação em fazer um vínculo de segurança com o paciente); “... o levantamento do comportamento cultural é interessante para entender os problemas e anseios...”; “... fiquei feliz em perceber que D. M.L. demonstrou equilíbrio e tranqüilidade diante de suas habituais cefaléias...”; “... Peculiar a personalidade e a forma de encarar a vida de cada uma. Aprendi muito conversando com ambas, principalmente ao perceber que os meus problemas são às vezes insignificantes diante de muita gente, como elas...” ( neste discurso, a aluna percebe a singularidade de cada paciente perceber a doença de forma diferente, numa demonstração clara de sentimentos humanísticos); “...por ter parentes no interior, pude entender bem algumas atitudes práticas. Entendi perfeitamente a aflição descrita pela entrevistada, quando soube que era portadora de doença no coração...” ( Aqui, o aluno demonstra identificação de cultura com o paciente. Neste caso, não se trata mais de um técnico frio, neutro, mas de alguém capaz de empatizar com a dificuldade do outro); “...principalmente entre os mais humildes e com nível de formação e esclarecimento inferior...”; “... o imenso desejo de viver, bem como um medo incontestável da morte...”; “... D.M. representou uma lição de amor e entrega incondicional da mãe a um filho, servindo de exemplo para todos nós...” ( as alunas se vêem como pessoas - futuras mamães - inclusive falando em amor, sinal de humanização); “...posso dizer que me senti feliz e satisfeita de poder aprender e admirar a cultura popular através da opinião da comunidade..” (Observa- 
se neste caso a evocação de um valor importante: a humildade, representada na disponibilidade de aprender com o outro).

O terceiro aspecto, apresenta uma Preocupação com o aperfeiçoamento da relação médico-paciente, que pode ser observada nos seguintes trechos dos discursos: “...Iluminamos o nosso bate-papo com conselhos sobre como deve ser o bom médico - atencioso, prestativo e amigo..."; "...o trabalho de campo foi muito proveitoso para se ter um conhecimento sobre as condições de vida da população de Barbalha...”; “... o levantamento do comportamento cultural é interessante para melhorar a relação médico-paciente...”; “... visitas como estas nos permitem experimentar o caminho das pessoas e facilita o processo de comunicação dos acadêmicos com a comunidade...”; “...estava mais relaxado, tendo em vista que havíamos visitado outra família anteriormente, e isso me proporcionou maior segurança...”; “...esta visita serviu para que a maioria dos meus medos e apreensões fossem extintos...” (observa-se nestes dois últimos discursos, que a visita também é percebida como muito útil para minimizar os medos e deixar o aluno mais seguro).

\section{Conclusões}

Ficou demonstrado nos relatos dos alunos uma maior compreensão das crenças populares em relação à doença e à cura, o desenvolvimento de empatia dos alunos pelos pacientes visitados e uma preocupação pelo aperfeiçoamento da relação médico-paciente, a partir desta experiência de pesquisa na comunidade. Portanto, aprofundar uma reflexão sobre a complexidade do exercício da medicina implica repensar a relação médico-paciente como uma forma de reafirmar a medicina como uma prática muito mais humana do que técnicacientífica.

\section{Referências}

OLIVEIRA JÚNIOR, W. A medicina não pode perder a emoção. Disponível em < http://www.simepe.com.br/campan.htm >. Acesso em 10/09/2005.

ROGERS, C e STEVENS B. De pessoa para pessoa: o problema de ser humano. $4^{\mathrm{a}}$ ed. São Paulo: Pioneira; 1991. p.103-20. 
SOARES, L. Avaliação da relação médico-paciente no atendimento ambulatorial de hospital universitário [dissertação]. Salvador: Faculdade de Medicina, Universidade Federal da Bahia; 1997.

TEIXEIRA, H e DANTAS F. O bom médico. Rev Bras Educ Med 1997;21:43-6.

\section{Outras obras consultadas:}

MORINAGA, C.V., KONNO, S.N., AISAWA, R.K., VIEIRA, J.E. e MARTINS, M.A. Frases que resumem os atributos na relação médico-paciente. Rev Bras Educ Med 2002;26:21-7.

NEVES, M.C.P. A fundamentação antropológica da bioética. Bioética. 1996;4:7-16.

SÁ JR. L.S.M. Evolução no conceito de ética médica. Medicina. 2001;127:32-6. 